\title{
The Paradigm of Transmediation: An analytical reading of the dynamics of comic strip translation with reference to select Nonte Fonte panels
}

\author{
Dr. Archita Gupta \\ Post Graduate Teacher in English, Henry Derozio Academy, Directorate of Secondary \\ Education, Government of Tripura. \\ ORCID ID:0000-0001-6030-141x. Email: architagupta82@gmail.com
}

\begin{abstract}
The present study focuses on the translation of a pure Bengali vernacular strip Nonte Fonte in English and to colour and its reception across the Bengali reading and speaking populace especially of Tripura, a North Eastern state of which the researcher is a part. At the same time this paper also highlights the way in which an apparently innocent comic strip such as Nonte Fonte showcases and disseminates, naturalizes and legitimizes stereotypes that represent negative codification of the cultural 'Other' (the inhabitant of Orissa relocated to Kolkata for work for instance) through its image /illustration medium and how the target reader internalizes it. Attempt has also been made to locate how market forces and the demand of English readership/target culture influence the translated product/text, thus pertaining to Bassnet's (2007) concept of cultural capital which can be loosely defined as that which is necessary for an individual to belong to the 'right circle' in the society (p.19). Translation helps a culture to come closer to the 'cultural capital' of the other. The concept of cultural capital is most pertinent to the power relation, concept of hierarchy and negotiation involved in translation in this context. Cultural capital here is not the Source Text (ST), but the Western canon of English language and English readership (global readership in English in this context that would generally define itself as a summation of the Bengali (with or without Bengali reading competence, but with English reading competence) and non- Bengali but English reading domains in India and the rest of the English reading world). However as has been pointed out later in this paper, the publisher tends to contain and restrict the consumption of his product- the text thus translated, within a supposed niche of target readership, the Bengali children. The paper also interrogates the impracticality of such a proposition.
\end{abstract}

Keywords: Image, translation, codification, transmediation, reader-response.

This paper attempts at analysing and theorizing comic strip translation and its reception in the broader perspective of intercultural communication. As comic strip involves semiotic environments, their translation from the perspective of inter-linguistic translation has been analyzed here highlighting their image-text relation. Translation process always runs the risk of losing the self/ source culture through translation into the Target Text (TT). As translation is often prompted by demands of the reader's space and market forces, attempt is also made to inspect

This Open Access article is published under a Creative Commons Attribution Non-Commercial 4.0 International License (http://creativecommons.org/licenses/by-nc/4.0/), which permits non-commercial re-use, distribution, and reproduction in any medium, provided the original work is properly cited. For citation use the DOI. For commercial re-use, please contact editor@rupkatha.com. 
the language hierarchy, hegemony and cultural dominance at play between both the Source Text (ST) and Target Text (TT) and their originating cultures respectively. The comic strip as a cultural text is composed of signs such as verbal/non-verbal, linguistic/pictorial, implicit/explicit, etc. They together form a matrix of codes that convey the message. The message is received by the viewer/ reader of the Target Text. The image/illustration exhibits that which cannot be expressed in language and also supports the verbal message thus facilitating translational process. But, at the same time the image/illustration also resists a cultural text to be translated into another culture through a reductionist and simplistic mode, since it does not undergo translation but 'transmediation'."This could be read as a strategy of resistance that ensures safeguarding the original/source cultural identity since total transculturation is partially resisted in the process of translating a comic strip.The result is a paradox-a binary of help and hindrance" (Gupta,2009; see also Gupta, 2012 ).

According to Federico Zanettin, comics translation should be seen ultimately as intercultural translation between semiotic environments that are culturally determined along dimensions of space and time. By semiotic environment he means a "multiplicity and heterogeneity of semiotic systems which encompasses texts, media and discourses i.e. the visual systems (such as illustration, caricature, painting, photography and graphics), temporality systems (comprising of narratives, poetry and music) and mixed systems of images and temporality i. e. cinema and theatre" (Zanettin,2004). McCloud suggests that "meaning in comics is to be found in the blank spaces between panels. It is the reader who fills in those intersectices with expectations and world knowledge and makes sense of sometimes seemingly incoherent images and words (as cited in Zanettin,2004). This is in conformity with Wolfgang Iser (1974) who is of the opinion that the literary text, as a product of the writer's intentional acts, partly controls the reader's responses, but at the same time contains a number of 'gaps' or 'indeterminate elements'. The reader by way of creative participation must fill in these 'gaps' or 'indeterminate elements', respond in specific anticipated ways to the "response-inviting structures" of the text, here the language-illustration combine of the comic strip in question (Iser 28). Zanettin, on the basis of Eco's recent and elaborated model discerns the following types of inter and intra-semiotic comics translation:

a) the change of reading direction often involved in Western translation of Japanese comics, as in Arabic translation of Western comics, the first consequence being the creation of many left-handed people;

b) the reproduction in black and white of a comic book in colour or vice versa (5)

Zanettin observes two approaches relating to comics in translation studies. The first one is the linguistic oriented approach. It views comics mostly as a source of example to discuss the translation of puns, proper names, onomatopoeias, citations, allusions and other features of language which are often found in comics, but not specific to them. The semiotics oriented approaches take into account features specific to the semiotic environments. These approaches take into consideration the relationship between symbolic and iconic components i.e. between written text and picture. However the relationship between visual and written elements can also be seen as complementary, whereas the interplay between "art form specific grammatical devices" 
such as frame transitions, motion lines, lettering, pictograms and visual metaphors contribute to the meaning and development of narratives.

Simundich (2009) refers to Zanettin's view on constrained translation that translation in comics further separates textual/written meaning from visual meaning. Although constrained translation approaches and stresses the semiotic dimension and the interdependence of words and images in comics, they remain primarily concerned with the translation of verbal material. Words are seen as subordinated to images and non-verbal components of comics are discussed only so far as they represent visual constraints for the translator of the verbal components. This approach assumes that picture in translated comics is not modified and thus often restricts the scope of investigation to linguistic analysis, an idea that curiously is in sync with the researcher's hypothesis of partial translation of comic strips, but comes as an advantage by resisting simplistic and reductionist transculturation and "cultural ventriloquism", a term used by Ashes Gupta while analyzing the Author-Translator hegemony in English Translations of Kokborok Poetry. He questions whether translation is ultimately an act of cultural and linguistic 'ventriloquism', where the author's voice and identity in translation are those of the translator's conveniently replaced. (Gupta,2009, p 110) As cited in Simundich's (2009) article, Zanettin notes that the paratext of international comics has changed as a result of new transcription methods; for Zanettin artists looking to adapt their works for an international audience structure their texts on familiar "translatable" visual resources as it happens in the case of Nonte Fonte comics translated to English.

This aspect of translation process is connected to and can be analysed according to Bassnett's concept of "textual grid" that seems to exist in all cultures in ways that pre-exist language. The grids are constructs, they reflect "patterns of expectations" that have been internalised by members of a given culture (17). The idea of textual grid is helpful in analyzing comic translation of comic strips. In an essay that developed his thinking around the idea of textual and conceptual grids, Andrew Lefevere asserted that problems in translation are caused "at least as much by discrepancies in conceptual and textual grids as by discrepancies in languages".(as cited in Bassnett, 2007 ). As far as textual grids are concerned, the translation of Nonte Fonte in English attempts to conform to the patterns of expectation of a global English readership by a thorough modification in the quality of the product. Here the vernacular Source Text (ST) text/ product is being 'translated' into the Target Text (TT) / cultural product of the target culture and language. Nonte Fonte's translation in English is also an attempt to acquaint Bengali children with the rich cultural heritage of Bengal who do not possess Bengali reading competence because of the tendency of Bengali society that considers Bengali to be lower in hierarchy in comparison to English (an instance of language shaming). Hence ironically the process or the initiation to be acquainted with one's own culture and heritage is attempted through a language which is not one's own. The supremacy of English language in the language hierarchy is operational here and points out to one of the crucial factors of translation process in its broader perspective. Viewed from this perspective Nonte Fonte's translation into English is dominated by two extra textual factors in the translation process - language hierarchy and the effect of market forces. The hierarchy of Source Text and source culture and Target Text and target culture is subverted as the 
former dominates because of the prominence of the target language. The importance of retaining the nuances of source culture through illustration becomes pertinent here as comic strip translation does not allow total translation (the preferable term would be transmediation in the context of this paper's title) because of its visual (image/ illustration) quality. Hence, Nonte Fonte's translation into English suffers if viewed linguistically. It often misses the culture specificity and the genre /textual specificity of the comic strip in particular and children's literature in general from the linguistic point of view. However, it cannot be denied that translation of Nonte Fonte comics into English is more inter-lingual than intercultural as the target readers here belong to a category of different language habit, but not different cultural habit. But to generalize in such way would be an oversimplification since culture-language parameter is a complex one.

In Nonte Fonte Unmatched, the translated version of Nonte Fonte Lajabab in Bengali, the comic flavor of the series is retained through the illustrations and compensates the lack/impossibility of perfect equivalence to be attained through translation of some of the colloquial and really humorous terms in Bengali. In the second and the third panel of page 3 ,the illustration of the superintended lying in bed due to severe stomach ache reveals much more than the linguistic text forcing the reader to comprehend the 'painful intensity' of his condition.
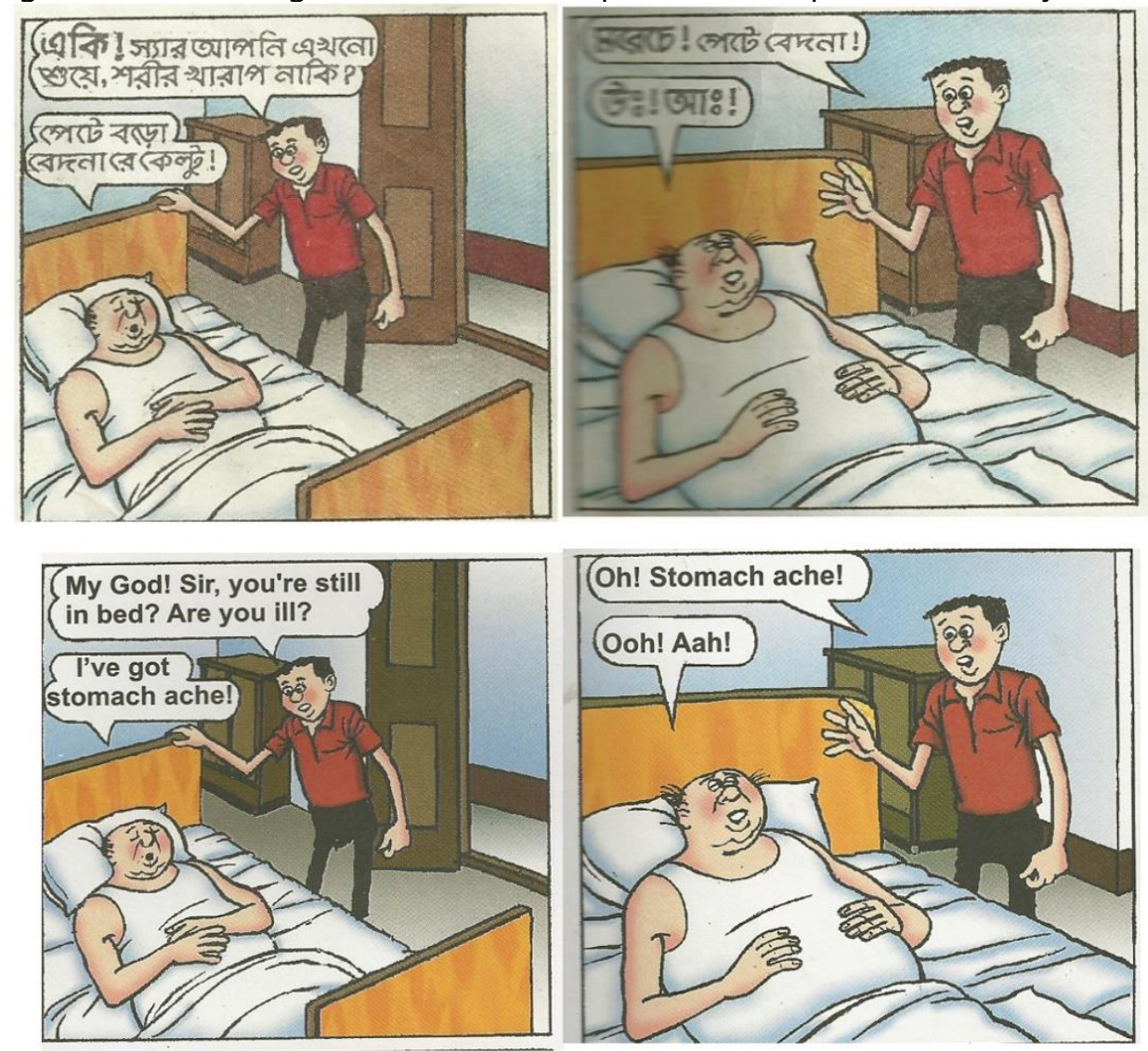

Figure 1. 
The linguistic text however fails to convey this in English. The translated text "I have got a stomach ache" is nowhere equivalent to the Bengali "pete bado bedana re Keltu!"(figure 1). It neither conveys the pain nor renders the humour associated with the genre. The "ooh! aah!" in the speech bubble, is specifically an attribution of comic genre and can not properly be called a' translation' of the Bengali Source Text. Comic Strips facilitate a semiotic system that works through the relation between written text and pictures which are easy to be encoded. Illustration in a comic strip helps in grounding the text in a specific socio-cultural milieu and functions almost like an 'establishing shot') in film making. It is an usually a wide shot (also called a long shot), an extreme long shot, or an aerial shot that shows a lot of the setting for context.Comic strip as a text offers a cultural representation of the context, both through language and the image. The translator mediates between two linguistic and cultural systems and should possess not only bi-lingual ability but also bi-cultural understanding. The translator mediates between cultures including ideologies, moral systems, power equations et al. The concept of comic strip translation necessitates viewing from a different perspective altogether because of the uniqueness of the genre.Eisner (2008) defines comics as "the arrangement of pictures or images and words to narrate a story and dramatize an idea" and explains that "in its most economical state comics employ a series of repetitive images and recognizable symbols. When these are used again and again to convey similar ideas, they become "a language -a literary form, if you will". In fact, the text -picture synergy of comic strip offers a kind of translation that can be defined by the term 'transmediation'. It is a translation /transformation of ideation effect which does not consist of a single sign system/single creation, but a combined form of two sign systems that produces a greater literary effect. Siegel defined transmediation as "taking understanding from one system and moving them into another sign system" (as cited in Ting) and the title of this paper thus derives justification from this argument. Reading of comic strip involves going back and forth between pictures and language and the reader frequently translates his/her ideas from one sign system to another.

As far as textual grids are concerned, the translation of Nonte Fonte in English and to colour attempts to conform to the patterns of expectation of a global readership by a thorough modification in the quality of the product. Here the vernacular text/product is being 'translated' into text/ cultural product of target culture. This paper also investigates the different concepts of inter semiotic translation in comic strip and how it becomes a mode of cultural production and cultural dissemination. A translation process is sometimes necessitated by the prospect of ability of the translated 'form' to generate meaning in the target culture and its dissemination. As the term 'text' is now used in the post modern sense, translation is not limited to language-tolanguage translation only, it can be from one genre/medium to another i.e from 'text' to 'text'. The translation of vernacular comic strip Nonte Fonte to color strips where language or verbal components remain unchanged and to English has been the praxis for case study in this paper. Attempts have been made to show how the translated forms of these strips work as a product as well as producer of culture and cultural artifacts. Translation process in the present study offers a different situation as Nonte Fonte's translation to colour strip and to English ironically does not aim to go beyond the Bengali populace as target readers as stated by the publishers (but the 
question is can this be thus contained?). The article "Return to Roots" by Debaleena Sengupta in Business Standard interestingly describes that Nonte Fonte translation in English is an attempt to acqauint Bengali children with the rich cultural heritage of Bengal. In fact an initiative has been taken by a leading publishing company of Bengali literature to translate Bengali classic children's literature into English to familiarize them to their roots and let them know "what their parents grew up reading". The translation, at the same time, is an attempt to compete with the English books dominating the market. As cited in the article, Arabinda Das Gupta of Dasgupta \& Co. says that "... due to poor print and graphic quality because they are cheap, Bengali books suffer when faced with superior quality English comic books like Tintin, Asterix and Tinkle" According to him, the translations will help draw children towards Bengali literature and folklore. But ironically the process or the initiation to acquaint children to their own culture and heritage is done through a language which is not their own. The supremacy of English language in the language hierarchy operates here and emerges as one of the crucial determiners in the translation process. The problem of translation is cultural not individual. The individual mind operates in a cultural context. Therefore when we translate it is not the propositional knowledge ascribed to the individual mind which is involved, but rather translation is the communication of cultural knowledge. Every act of translation is a social act, involving social relationship; transforming as well as transcending boundaries. Translation, therefore, in its broadest sense can refer to a cross-cultural understanding. But translation always involves an ideology. The ideological implications of translation is noted by Bassnett when she says that all rewriting, whatever their intention may be, reflect a certain ideology and a poetics and as such manipulate literature to function in a society in a given way. Rewriting is the manipulation, undertaken in the service of power and in its positive aspect can help in the evolution of literature and a society (as cited in Rubel, 2003). Cronin notes that translation relationship between minority and majority languages are rarely divorced from the issues of power and identity that in turn destabilise universal theoretical perception on the translation process (ibid). And it is exactly here that Bassnet's concept of cultural capital (Bassnett, 2007) comes to play. As has already been pointed out in the very beginning, cultural capital here is not the source text but the Western canon of English language and English readership (global readership in English in this context that defines itself as a summation of the non- Bengali but English reading domains in India and the rest of the English reading world). The ISBN in the translated text is also an indicative of the process. What is being marketed both in the ST and TT through image and text combination is a depiction of characters and events with the essence of Bengali culture. These comic strips are targeted to a readership embedded in Bengali culture (as claimed by the publisher) covertly reinforcing Bengali cultural value also to a non-Bengali yet Bengali reading audience unconsciously subjected to cultural hegemonisation.

The process of negative stereotyping in the form of illustrations operate even in the translated text resulting in attributing a monolithic, fixed and subordinate identity to the cultural 'Other' who in all probability are readers from other culture. Illustration resists translation in comic strip. Therefore, translation to English language reinforces the ideology of the source text. The combined sign system of comic strips operates through cultural codification where representation to lexical -visual combine leads to recognition or identification. Sign plays a very important role in cultural production since the latter is the production of a system of thing, sign values that inform not only our practical function but also our social relation, making of our individual and collective 
identity and affirming the social relational network in which we are embedded. Therefore over a period of time signs gain a permanent significance and the repetition of sign becomes norm and consumption of such a system of signs become legitimized, and therefore any representation /negative codification/stereotyping seems natural. In this regard it becomes pertinent to quote Michael Pickering, who in his seminal work Stereotyping. The Politics of Representation (2001) defines stereotyping thus: "as a process for marking, maintaining and reproducing norms of behaviour, identity and value" (174). Thus a person from the other culture (the cultural 'Other') is often assigned subordinate status and the negative codification embedded in the sign system reinforces this cultural bias instead of being lost in translation process. A panel from Nonte Fonter Nanan Kirti Vol. 7,8,9 (page 10 of 7) can be analyzed so as to show the function of text and image and depict how this combined code type of text generates meaning. The panel shows the Oriya cook telling Nonte Fonte and Keltu that superintendant is calling them (Figure 2)

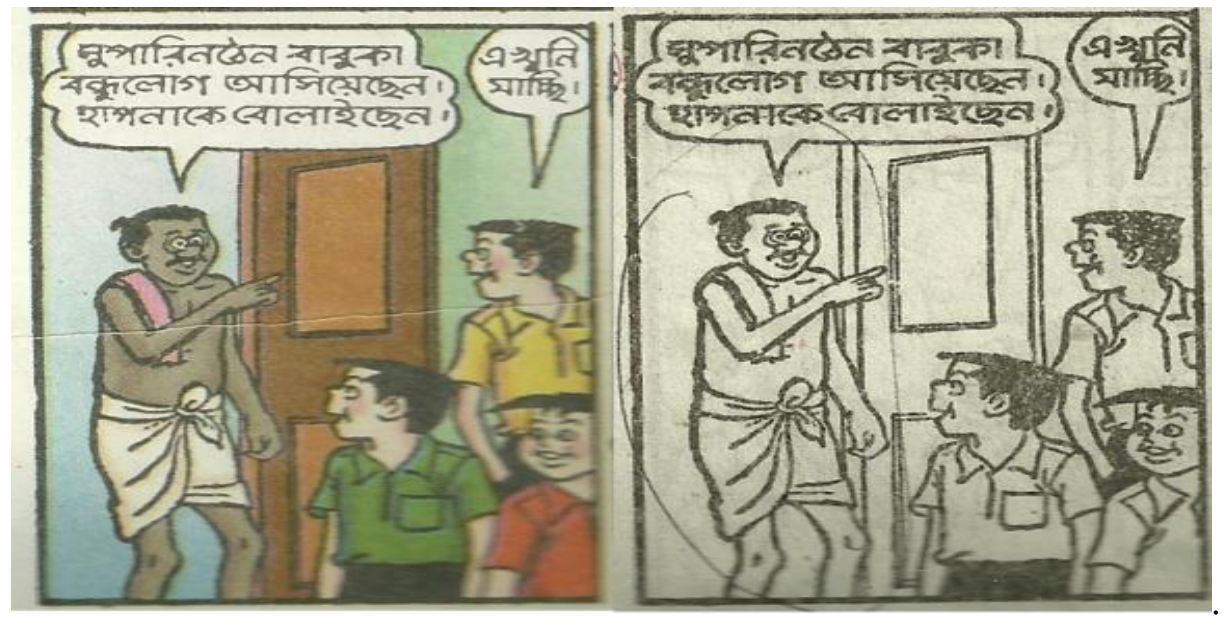

Figure 2.

The image provides scope to decipher the text through the illustration where he is shown to be informing them (the body language and expression). Even if the relay text is omitted we can still decode his subordinate position through his role as a cook and as someone who functions as a bearer of order. His illustration with a 'tiki' and 'gamcha' ${ }^{6}$ directs the reader /viewer to his identity that is generally referred to as 'Ure Bamun' in Bengali meaning a low category Brahmin (not the pujari or priest category of Bengali Brahmins) engaged for cooking only. The anchorage text here constructs a fixed meaning that operates in consonance with dominant power structure /hegemony where his subordinate role is emphasized in contrast to the mainstream BengaliHindu culture. Calcutta has a history of enjoying socio-cultural, literary and economic privilege due to politico-geographical reasons. People from Orissa, Bihar and other comparatively underdeveloped regions came to Calcutta primarily in search of employment. A Brahmin from Orissa would have to work as a cook in a house, a profession that would be of a lower rank in racial hierarchy. The social hierarchy of his society and culture of origin viz. Orissa society where he enjoyed dominating position was thus reversed due to economic reason, dislocation and displacement as well as change in society and culture. A 'central' thus became 'marginal'. This 
becomes even more pronounced in the colour version of Nonte Fonte as has been discussed later in this paper. The relay text that is complementary to the image is the language spoken by the cook ("Thakur"). He is trying to speak Bengali language with his own mother tongue accent and intonation. Language is a means of communication and he is bound to communicate his ideas into the language of the 'other' culture as he occupies a peripheral/marginal space in that culture and society (here Bengali). His role is strengthened through relay and anchorage which implies that ideology operates in comic strips/comics or visual media more forcefully through these combined types of text. The more a signifier is constrained by the signified, the more motivated the sign is. Iconic signs are highly motivated in comparison to symbolic signs. Greater learning of an agreed convention is required when a sign is less motivated. Comic strip illustration requires less learning to consume what is depicted or illustrated and is therefore more effective than linguistic text. The following diagram may be helpful in analyzing the process of communication of the message in case of Nonte Fonte comic strips

\section{Iconic sign + signifier $=$ signified}

Illustration of Nonte or Fonte + drawing of dress, gestures, appearance (pictorial code) etc along with verbal Bengali speech corresponding to mainstream (linguistic code) = A Bengali boy of Thirteen or fourteen years old

OR

Illustration of cook+ drawing of his dress, gestures, appearance (pictorial code) etc along with his verbal speech with a mixed accent corresponding to a culture which is not specified or to a virtual non-recognized identity (linguistic code) $=A$ person with subordinate position with an unidentified identity who does not belong to mainstream, an outsider or the cultural 'Other' with respect to 'self'.

The following diagram can show how a sign becomes meaningful at the connotative level:

$$
\text { Sign = image + verbal dialogue }
$$

Oriya cook: "superinten babuka bandhulog aasiacchen, apnake bulaichen".

(The friends of Superintendent Sir have arrived, you are being called (trans. Mine)

\section{Denotation}

(a person calling three boys) 
9 The Paradigm of Transmediation: An analytical reading of the dynamics of comic strip translation with reference to select Nonte Fonte panels

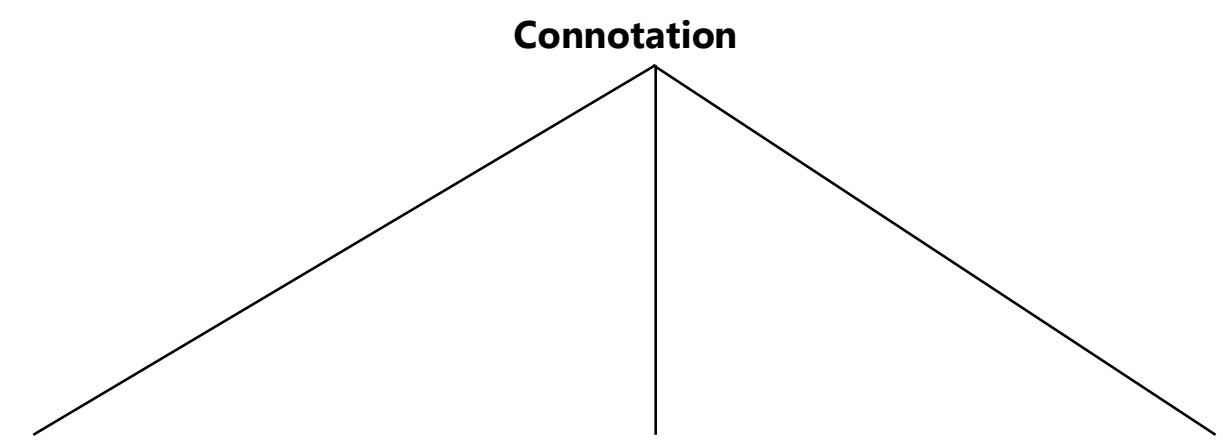

Carrying orders subordinate loyal/ruled.

The illustration of the cook and his broken language as an attempt to make him comprehensible in the Bengali cultural context is the dominant code that the target audience has access to and thus they interpret the 'text' at the connotative level.

Comic strip presents a complex phenomenon with its 'non-serious' implication because of the medium employed and the 'serious' cultural/ hegemonic bias at play. The interpreter of a comic strip of the kind of Nonte Fonte with the social knowledge (here the knowledge of Bengali culture) shall employ a dominant social code to decipher its meaning. While employing these codes, the receiver/interpreter of a dominant culture would definitely subordinate a character of different culture (such as an Oriya cook frequently seen in Nonte Fonte as marginal. The medium (image/illustration) here emphasizes the interpretation/decoding with its visual quality.

An analysis of Nonte Fonte's translation to colour strips would reveal the front cover of the three coloured strips (of the coloured series) in Nante Fante Banaam Keltuda ('Nante Fante Versus Keltuda', trans.mine), Nonte Fonte Lajabab ('Marvellous Nante Fante', trans.mine) and Best of Nonte_Fonte (Figures 3 and 4) have contents in colour within the cover. It can be pointed out that both the cover and the pages have an improved quality of paper in comparison to the black and white strips. 

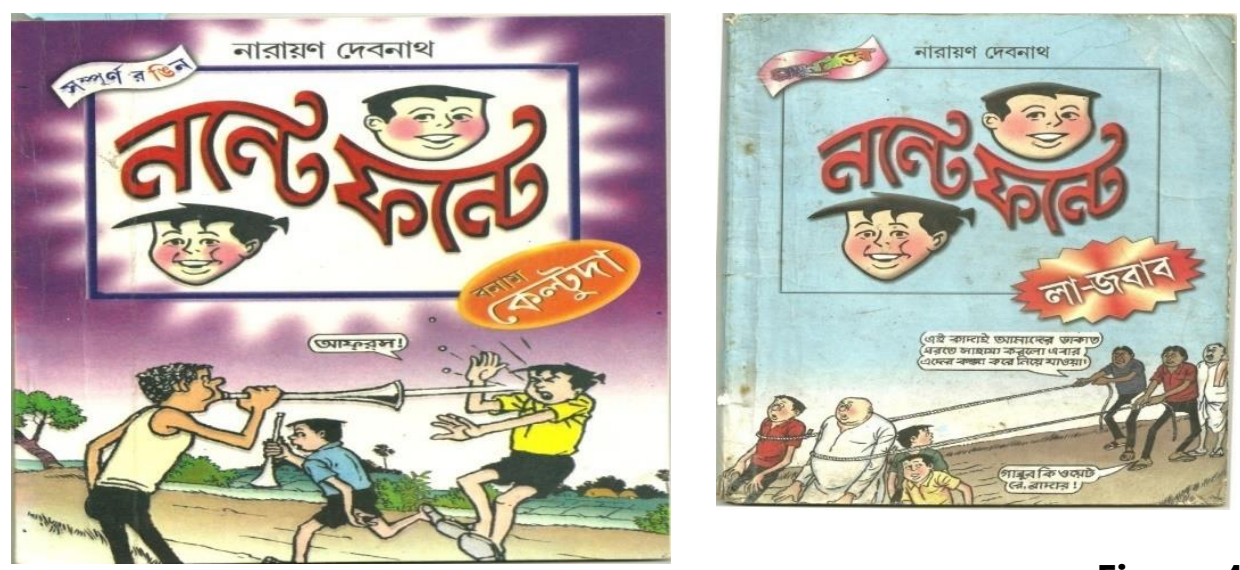

Figure 4

The prices of the strips have also been hiked. This is, however, a marketing strategy that attempts to expand to a larger readership. Differences can also be located in covering the whole 'text'. Unlike the black and white strips, these strips allot another page apart from the cover (the dedication page) that includes apparatuses such as name of the author, name of the publisher with address, name of cover designer and price tag. All these function as codes to refer to this new product as a text of recognition. Here a change in addressee has been attempted by changing the look of the text. It also serves as a code, as the look and the quality of binding of the text, for instance, generate different kinds of expectations on the part of the reader. Both the front cover and the back cover have illustrations from Nonte Fonte only. The apparatuses have tried to create a space/world of their own. It is a code that triggers a decodification of Nonte Fonte comics as a separate or better kind of reading material from what has been done so far. As the back cover of all the three texts is same, it is relevant and pertinent to point out that it as an attempt at creating a homogenous whole regarding the publication of 'Rongin Series' ('Coloured Series', trans. mine). The back cover includes all the characters of the 'message' (the contents of Nonte Fonte colour series). In the left lowermost part of the back cover Hostel Super and Keltu are sitting in the dining table and the cook is attending to the orders of the latter. Colour here is a code in triggering the hegemonic bias at play. The cook is given a much darker skin tint in contrast to the 'central' characters (see Figure 5 )

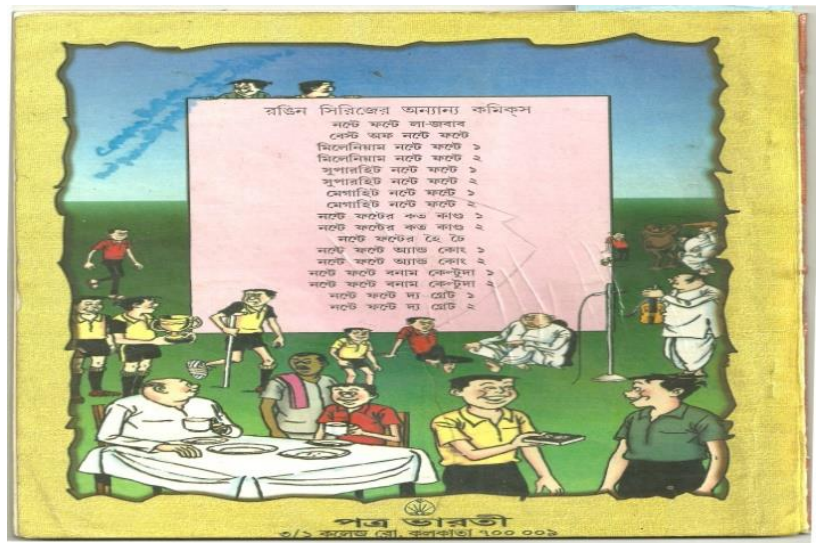

Figure 5 
In the context of the text it can be easily decoded that he is of different/inferior origin from them as in socio-cultural background and aesthetics of the Bengali majority culture, people with fair complexion are supposed to be superior, are generally favored and are considered to belong to a higher birth. Among the other illustrations, the childish, mischievous yet 'masculine' activities of Nonte, Fonte and Keltu are given prominence. This functions as a code in generating an expectation regarding the contents of the text on one hand and creating a central-male/marginalfemale hierarchy by excluding girls from the content on the other. In the bottom centre there is a logo of Patrabharati Publications with address and in the top there is a board held by Nonte and Fonte. The board contains the list of other comics ('text') of 'Rongin' Series. This is, as has been pointed out earlier, an attempt to create homogeneity of colour strips as a part of a marketing strategy that follows a pattern of uniform and homogenous codes. Before analyzing the front covers of other black and white strips, a comparison should be drawn between the back covers of colour and black and white strips to reinforce and validate the point as to how codes play a prominent role in generating /influencing meaning of a text. The back covers of black and white strips -Nonte Fonte Collection (16 for instance) fail to create a homogeneous space for Nonte Fonte series only because of the lack of homogeneity of codes.

The top-most space includes the covers of Kishore Bharati, a magazine published by the publisher of Nonte Fonte. The front covers of the series of Kishore Bharati are given in a purely advertising style. Another strip from the same publication is projected along with Nonte Fonte covers. This cover as a code would not trigger the expectation so much as that of the back covers of colour series. The later attempts to occupy a place enjoyed by translated foreign comics in Bengali (such as Tintin or Aesterix) in the target readership. This paper here proposes to question as to whether this can be examined as a move from margin towards the centre). However for a serious reader looking for connotation, the attempt itself is a code as it reinforces its supposedly subordinate status.

An analysis of front cover of any one such comic strip production in colour from the perspective of functionality of codes would reveal some interesting insights in the reading of such texts.

(1) The title Nonte Fonte Lajabab is written in a curved, easy going style with bold fonts. The particular style is a code to refer to the fact that the contents or message of the text would not be gloomy or serious. In the corner of the title the tag 'SAMPURNA RANGIN'('Fully Coloured', trans. mine) is a code for the target audience, who are, in all probability, already familiar with Nonte Fonte black and white series, that it would be more attractive than before and would have to be decoded as intended.

(2) It has employed a sign as a code particularly encoded to refer to the text in close affinity with cartoony style as is seen in Tom and Jerry cartoon. A reader would definitely decode the text as very closely associated with the amusement element of cartoon. It is a code used as an attempt to place the text in the same canon with more similar 'texts' of popular literature in print and visual media. 
The construction of the superiority of Bengal can be further located if we examine the same panel that is used in the context of denotation and connotation. The point to be noticed is the association with 'Oriya' (belonging to Orissa) and therefore subordinate that is an extension of the phenomenon of negative codification already referred to earlier in this paper and revalidates the latter's hypothesis. Through the coloured image of the cook we cannot conceive Bengal as superior directly, but at the connotative level the image communicates marginality. It becomes an accomplice to the concept of Bengal as superior. The knowledge of codes of interpretation which are functional here is the knowledge of discrimination between high and low or hierarchy that is true for all cultures and reveals how hegemonisation functions through various connotative frameworks. In the Best of Nonte Fonte 21 the writer/illustrator gives the cook a rather dark complexion in contrast to the main Bengali characters. He is seen both in the back cover of the collection and also in individual stories. Being a coloured strip, it shows the contrast not only in language but also in the image prominently. His 'paite'(the sacred white threadworn across the chest slung from the shoulder generally by the Hindu Brahmins) and 'tiki',(small ritualistic tuft of hair to serve usually at the back of the head to serve as a marker for a caste or creed such as the Brahmins and the Vaishnavites) the indicator of his upper caste, are seen but he is shown standing in wait and serving beside the dining table both in the back cover and the panel. A person from Orissa need not necessarily be dark. While all the Bengali majority characters are illustrated as fair, a contrast/discrimination has been drawn here between centre and periphery through the colour code. People of rural background are also given a dark complexion so as to draw a dividing line between high/sophisticated urbanity and low/illiterate rurality consciously or unconsciously. Culture, like sign, also constructs or formulates meaning out of difference. The 'negative' attribution of the sign (image + dialogue combine) of the cook is determined by connotation and is understood through the contrast of 'positive' attribution of the other sign system. The writer/ illustrator uses a particular character and image to be decoded in a specific programmed manner by target readers. The usage as well as the responses thus generated are both context specific. As far as Nonte Fonte comic strips are concerned, the writer/ illustrator by projecting a particular image avoids unnecessary explication and detailing in language (the dialogue of the person concerned) and also provides the reader/ audience with 'gaps' and 'indeterminate elements' to be deciphered from the reader's own cultural contexts. Because of the illustrative quality of the comic strips, the connotation tends to become fixed unlike other literary texts. Nonte Fonte is a comic strip written in the cultural context of Bengal and the target readers are supposed to be Bengali children (with Bengali reading competence in case of the Bengali version and also, as intended by the publisher, Bengali children with English reading competence who do not possess the same in their mother tongue, in case of the translated English versions) primarily. The target reader is the implied reader who is established by the text itself. When asked about preference in reading comics a six year old child reading in English medium school responded that he does not read Bengali Nonte Fonte comics because he finds difficulty in reading Bengali but a regular viewer of Sinchan, Doraemon, Ben10, Power Rangers, Chota Bheem,Amar Chitra Katha,.Ramayana-the Legend of Prince Ram,Krishna and Balaram, Mickey Mouse, Handy Many , Chota Bheem aur Krishna,etc.He prefers reading English comics as they have glossy cover and human like drawing. His perception of Nonte Fonte as drawings and Tintin and kochikame as human beings is based on the assumptions that lines in the body of kochikame appears in their face when they speak. It also points out that a realistic drawing appeals to a child more than one 
line drawings. The functionality of codes in generating response leading to an unconscious internalization of visual code as natural and permanent is validated by child's response to his choice of colours. He used body colour(interestingly to a child 'body 'colour takes its name because of its repeated usage) to human beings and green and black to Rakhsasas because the Rakhsasas are always shown like that. (Debnath, Sourasnata. Personal Communication, October 23,2012).

It is relevant here to relate the comment of the writer / illustrator of Nonte Fonte comics Mr. Narayan Debnath. When he was asked about the negative codification or stereotyping in his strips, he commented that it is a general tendency of people of one region to neglect people of other region (Debnath, Narayan. Personal Communication, January 1,2011. The truth that was thus elicited is that a text does not only conform to such tendencies, but also naturalises and legitimizes them. Here lies the concept of the implied reader, one whom the writer/illustrator simulates as an imaginary model of his target reader, automatically loading him with his ideological bias and values. When Narayan Debnath naturalises the existence of stereotypes and cultural dominance, he is anticipating the target reader from his understanding of the implied reader in his mind simulated in his own reflection. A text thus becomes a space of participation for the creator and the consumer, the author and the target reader. When a text is created keeping in view the implied reader who anticipates the target reader who shall participate in decoding it, the text automatically becomes a product not only of the writer/ illustrator or publisher, but also of the target reader who consumes it.

Stanley Fish(1980) follows the experience of a 'reader' word by word insisting that what "happens to, and with the participation of, the reader" is in fact the "meaning" of a text (Fish 25). But this relates to an abstraction coined by Fish- 'the informed reader'. Fish argues that real readers can become informed readers by developing linguistic, semantic and literary competence, by making their minds the repository of the (potential) responses of a given text" and by "suppressing, in so far as that is possible ... what is personal and idiosyncratic"(ibid). The 'suppression' of the personal in case of popular literature (such as comic strips and more specifically Nonte Fonte) would lead to a failure in the expected reception as such texts are very much context and culture specific, focusing at 'local' rather than the universal or general category. Narayan Debnath, the writer/ illustrator of the strips spoke about the ridicule he faced for his "Bangal" (a term used to refer to people of East Bengal) identity when he came to Bengal. The reason of inclusion of this fact in this context is that when a text is produced (or even reproduced in translated/ modified form) it is linked to culture and history as well. Susan Bassnett suggested that translation offers an ideal laboratory situation for the study of cultural interaction, since a comparison of the original and the translated text will not only show strategies employed by translators at certain moments, but will also reveal the different status of the two texts in their several literary systems. More broadly it will expose the relationship between the two cultural systems in which those texts are embedded. (Bassnett 20). It is necessary to mention here that the time frame depicted in Nonte Fonte is that of Bengal in 1960's. According to the writer-cum-illustrator, he depicted Nonte and Fonte remembering his days in Shibpur, West Bengal. The illustrations of central characters, their behavior, mannerism, dress and the peculiarities associated with the then boy's hostel have 
probably remain unchanged through time. It is another authorial intention that can also be termed a stimulator of nostalgia.

Thus it can be observed that in the case of a comic strip translation (rather transmediation) such as Nonte Fonte from Bengali to English and to colour, there are several factors that come to play in influencing what could be most appropriately termed as transmediation. This takes in to account the covert strategy of the source culture to produce and disseminate cultural stereotypes through negative codification of the cultural 'Other'. The naturalization and legitimization of such connotations through the comic strip medium cannot be ignored in any analysis of comic strip in transmediation, as the textual and visual analysis of select Nonte Fonte have substantiated, further validating the hypotheses of this paper.

\section{References}

Bassnett,S (2007).'Culture and Translation' Topics in Translation.13-23. A Companion to Translation Studies. Multulingual Matters Limited. Clevedon.

Banerjee, S (2011). Nonte Fonte Unmatched, Kolkata: Bee Books. 2011. Print

Sengupta ,D (2011, March 27) .Return to Roots. Business Standard. March 27, 2011. Business

Standard.com. <http://www.business-standard.com/india/news/return-to-roots/429887/>

Debnath, N (1998). Nonte Fonte Collection .vol.7.8.9, Kolkata: Patra Bharati.

---Nonte Fonte collection. Vol. 4,5,6, Kolkata: Patra Bharati.

Debnath, N (2002). Nonte Fonte La-jabab, Kolkata: Patra Bharati .

(2005). Nonte Fonte ki Ananda Kolkata: Patra Bharati .

Deb, S. (2011). Nonte Fonte Hurrah Kolkata: Bee Books.

Eisner, (2008).Comics and Sequential Art. W.W. Norton and Company.

Fish, Stanley. (1980).Is There a Text in the Class? The authority of Interpretative Communities. London: Howard University Press Iser,W.(1974). The Implied Reader: Patterns of Communications in Prose Fiction from Bunyan to Beckett. John Hopkins Press: Balitimore.

Gupta, A (2012):Analyzing Comic Strips as a Mode of Cultural Production and Cultural Dissemination[Unpublished Doctoral Thesis].Tripura University(a Central University).

Gupta A (2009).Paradox of Illustration: Facilitating/Resisting Translation in Comic Strips. Translation Today 6 (1and2), 125-133.

Gupta A(2009).Translation as an Act of Ventriloquism: The Author-Translator Hegemony in English Translation of Kokborok Poetry. Translation Today 6(1and2), 107-114.

Iser, W. (1974). The Implied Reader: Patterns of Communications in Prose Fiction from Bunyan to Beckett. John Hopkins Press: Balitimore.

Pickering, M (2001) Stereotyping. The Politics of Representation. Palgrave. 
15 The Paradigm of Transmediation: An analytical reading of the dynamics of comic strip translation with reference to select Nonte Fonte panels

Rubel, P.G and Roseman, A (2003) 'Translation and Anthropology'. Introduction. Translation and Anthropology: Perspectives on Translation and Anthropology. Eds. Paula G Rubel BERG.Oxford. 2003.

Sengupta ,D (2011, March 27) .Return to Roots. Business Standard. March 27, 2011. Business Standard.com. <http://www.business-standard.com/india/news/return-to-roots/429887/>

Simundich, J (2009). 'Surrounded by Stillness and Quiet: Translation, Transparency and Genre in Jason's Jernvognen'. Image- Text Interdisciplinary Comic Studies.5(3).

<http://www.english.ufl.edu/Image-Text archieves/v5-3/simundich. >

Ting, Y. (2011) 'From Ponyo to "My Garfield Story": Using Digital Comics as an Alternative Pathway to Literary Composition'. Childhood Education. Summer <.http:/www.highbeam.com/doc/1G1-254482672.html>.

Zannetin, F. (2004,November).Comics in translation studies: An overview and suggestions for research. <http:/1086820439574408617-a-1802744773732722657-s\sites.googlegroups.com/site/federicozannetin/dbpublications/comics-in-translation-studies/html.

Dr. Archita Gupta has done her ph.d on the topic "Analysing Comic Strips as a Mode of Cultural Production and Cultural Dissemination". Her areas of interest include popular literature, translation ,cultural studies, folk tales of Tripura, etc. 